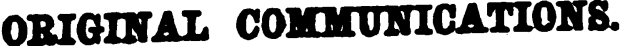

\section{THE USE OF AN EXTRACT AND DECOCTION OF THE COMMON STINGING NETTLE IN SOME CHRONIC SKIN DISEASES.}

By JOSEPH BULLAR, M.D., Physician to the Royal South Hants Infirmary.

Tas history of medicine supplies no grounds for the contemptuous rejection of the virtues of common indigenous plants because their promulgators are the poor and the ignorant, but the contrary; as it is well known that the knowledge of some of our most useful medicines has been owing not to scientific reasoning and experiment, but to a tradition of their efficacy handed down from an unknown source, and through ages darker in science, by those careful guardians of such traditions-the common people. Indeed, he who is desirous that his medical brethren should place in their materia medica an indigenous plant not yet raised to pharmaceutical dignity, can have no surer claim for credence than his total disclaimer of its original discovery, and the acknowledgment that no acuteness, reflection, no physiological, pathological, or therapeutical knowledge of his own, are his grounds for belief, but simply that the class of peasantry usually termed "old women" have recommended the herb on a traditionary empiricism, and that it has succeeded in his own hands after a sufficiently extensive trial.

That many medical practitioners in the country may have been in the habit of using the common nettle in skin diseases, I have little doubt. I happened in the first instance to try it from finding that a child affected with inveterate lichen agrius had been greatly benefited by the use of "nettle tea," prescribed as a domestic remedy after the failure of my own treatment; and from learning about the same time, that a boy whom I had once seen, and who was subsequently under the care of a celebrated authority on skin diseases, and was affected with one of those inveterate and extensive varieties of impetigo, which, in a cachectic state of the system, one is apt to look upon almost with despair, had perfectly recovered by the use of the same remedy.

On a further trial I found that many chronic diseases of the skin, especially in a cachectic state of the system, vielded with considerable rapidity to this decoction; and as it seemed a valuable remedy, I requested Messrs. Randall of Southampton to prepare an extract, which, on repeated trials, I have found to possess the same medicinal virtues as the decoction, and to have the merit of being more convenient and agreeable, and in cities more easily obtained.

The following cases illustrate the curative powers of this medicine.

CA8B I. A young lady, aged 14, of strumous habit, had been liable, for some years before I saw her, to occasional eruptions of psoriasis diffusa in large patches over the flexures of the knee and elbow-joints, attended with considerable redness, irritation, and heat. Twice (in December 1849 , and June 1850 ,) it was removed by liquor arsenicalis prescribed by myself. The arsenic gave her headache; so that she was averse to take it. The eruption returned a third time after an interval of three or four months (November 1850); patches of psoriasis also appeared on her forehead, neck, and chest, and resisted the liquor arsenicalis although given for several weeks. I then ordered a quarter of a pint daily of the decoction of the urtica dioica, made by boiling an ounce of the leaves and stems in a quart of water until it became a pint. She rapidly improved, and after taking fire pints was completely cured, and has had no return. The only effect she perceived was an improvement of her appetite.

Casz II. Mary C., aged 30, pale and cachectic, with habitually costive bowels, had a dry, chronic, scaly eruption murrounding the anklo-joint and lower part of the right leg, of three Jears' standing. The ame disease had affected the whole leg; the uppere part had been cured, bat the

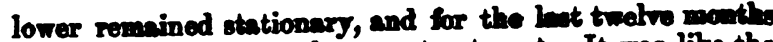
she had been subjected to no treatment. It was lite the remains of chronic eczems. She was ardered to take quarter of a pint of the decoction of nettle, and she returned in a month quite cured, having felt no other effect from the medicine.

CASE III. Edward H., a delicate boy, aged 4, had an inveterate eruption of lichen agrius covering nearly the whole of the back, chest, and abdomen, of two years standing. The edges alone showed its papular nature, the rest, from inflammation and scratching, was covered either with dry scabs, or with thin scales, thickening and hardening the skin itself. I recommended that he should take half a pint of the decoction of nettle as his common drink, and he soon liked it. To ny surprise, in five or six weeks the whole eruption was removed, and his skin was clean, smooth and natural, and not even marked. In this case, the cure of the skin disease seemed to have been too rapid, as he was soon brought to me again complaining of pain in his loins, and looking pale and ill: his bowels were costive. These symptoms were relieved by mild aperients and alkalies. Subsequently there was a slight return of the eruption, requiring a return to the decoction. During its use he sometimes complained of pain in making water.

The rapidity of the amendment in this case of a chronic eruption. affecting almost the whole surface of the trunk, in a cachectic child, which had lasted two years, and was completely removed in five or six weeks, gave me a strong impression of the power of the remedy.

CASE IV. Edward W., aged 8, a delicate strumous child, of an unhealthy mother, had had for six months a patch of chronic eczema covering both eyelids, the eyebrow, and part of the cheek of the left side. It was covered with a dry scab. He was out of health, languid, and complained of headache. Constitutional treatment, with calomel ointment and subsequently pitch ointment, were of little service. He was then ordered a quarter of a pint of the decoction of fresh nettles daily. In a month, the eczema was well. He was much better in health, having lost the languor and headache. The ointment of nitric oxide of mercury was used locally.

The preceding cases are selected to prove the beneficial action of the decoction of the nettle; the following cases show that the extract has similar virtues.

Case v. J. S., aged 27, a strong man, of fair complexion and light hair, and of healthy appearance, had patches of chronic lepra covering the elbows and knees, and extending above and below them for a considerable distance. The diseased surface was covered with thick scales like white mortar, entirely obscuring the red surface beneath them. The eruption had existed twenty-four years. His general health was excellent. He had never taken medicine to remove it: but as he was now confined to his bed in the South Hants Infirmary with a broken leg, he was willing to have the disease removed, and was a very fit case to try the remedy. He commenced with five grains of the extract three times a day. After three or four days there was slight improvement: after sixteen days, when he had taken half an ounce of the extract, the improvement was striking, as the thick white scales covering the affected parts were removed, and the parts beneath were almost as smooth as natural. During the prevalence of dry easterly winds the disease was stationary, and the dose of extract was increased to twenty grains daily; and fire weeles after he had commenced it, he left the infirmary quite well, with only the marks on the skin where the eruption had been. He was conscious of no perceptible action of the medicine; but his breath had a smell of herbs.

CAse vi. W. L., aged 22, a young man with light hair, fair skin, blue eyes, and otherwise healthy aspect, had been covered with lepra valgaris for nine months. His body, legs, and arms, were closely spotted over with circular patches; and the forehead and hairy acalp were covered with a more diffused scaly eruption. He had been three months under the care of a physician in a neighbouring

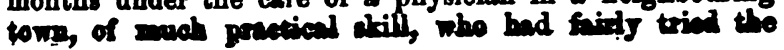


Bepar arsonicalis, but without any improvement. After - ing fire grains of the extract of urtics dioics three times a daj for \& week, the eruption itched more, but the scales were les numerous; and, on perserering for a month, the forchead and scalp were quite well, and the eruption on the body was fast dying awry; the scales diminishing, and the surface benenth becoming paler. At the end of six weeks, he reported himself as quite well, and I found the marks ane remaining.

CAsE vir. M. N., aged 40, a stout woman, who was nursing a child three months old, was admitted into the Bouth Hants Infirmary, with inveterate eczema impetiginodes of twelve years' standing. The eruption completely covered both hands and the forearms; and there were large patches on the arms, shoulders, chest, neck, and face, disfiguring her, and much interfering with her work, as her hands were chapped and sore. The itching was very troublesome. Her gencral health was good. She had been under medical treatment for many months by an experienced surgeon in the neighbourhood, who at last, as she did not improve, sent her into the infirmary. I ordered a warm bath and five grains of the extractum urticæ dioica to be taken three times a day. After taking this for a few days, she complained of a stinging feeling in her skin, which she had not had before. The eruption slowly but decidedly diminished. Her hands and arms, which had been covered with an agglomeration of pustules, vesicles, scabs, dry scales, excoriations, and deep chaps, were in about six weeks quite well. She was discharged eight weeks after admission, with merely the remains of vesicles on the shoulders and neck, and with directions to take the decuction of the fresh nettle at home. She returned, two months afterwards, perfectly well. During the course of her treatment in the infirmary, pitch ointment was applied to the eruption on one of the shoulders, to relieve the distressing itching, and with some advantage.*

CAs: viIr. 1. F., aged 8, a brunette, of a somewhat strumous organisation, but not unhealthy looking, though delicate, was affected with a dry, furfuraceous, hardened, and rather red condition of the palms and palmar surface of the fingers and thumb of both hands. They were chopped, and she complained that they were painful and itched. The complaint was of four months' standing. She was ordered to take five grains of the extractum urtice dioicæ three times a day. In five weeks (after taking half an ounce of the extract), her hands were well. They were free from pain and itching; the colour was natural; and there was no dry scaling epidermis; but the skin was not co soft as it should be, though no harder or drier than is natural to some hands. The general health was improved.

Case Ix. Ellen C., 11 years old, and of scrofulous habit, had been subject for eight years to unhealthy strumous sores on her hands. They commenced either as vesications or as flat livid tubercles, about the size of sixpence, and as much elevated above the okin: superficial ulcers formed, which healed with great difficulty, leaving white scars. Various means had been tried without success; and, as the complaint seemed to depend on a cachectic state of the system, I ordered, on April 5th, 1851, five grains of the extract of urtica twice a day. She rapidly improved; the sores healed; and the tubcrcles diminished in a fortnight. On leaving off the medicine, a few fresh vesicles formed; but, on resuming it, these healed, and in a month her hands were well. At the end of three months, there had boen no return.

CABE x. Elizabeth C., aged 6, a fine light-haired child, whose general health was usually good, but who was strumous looking, had been affected for some weeks by a dry papular eruption of the back, chest, arms, and legs, with come distinct pustules on the hands and arms. The papular eruption was lichen agrius; but the pustules had so much the appearance of pustular itch, and were attended by much itching that 1 ordered (October 18th) sulphur

- I am indobted for the notes $\alpha$ this and a previous caes to Dr. G. Lake,

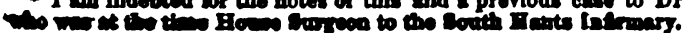

ointment to be freely applied, and diluted sulphnric acid with quinine twice a day. This was contined for twolro days, when the pustular eruption was quite rell, but the lichen was not improved. She was then ordered to take five grains of the extractum urtics dioicse twice a day.

Nor. 8th. She had taken two drachms, and the eruption was much diminished.

Nov. 28th. She had taken three drachms more, and the eruption was almost well. After this she took three drachms more; and her skin was then free from any eruption, and her general heslth excellent.

CASE xI. S. P., aged 15, on October 28th, 1852, had large patches of lepra vulgaris on the legs, and smaller ones on the thighs, of two years' standing, and gradually getting worse. Menstruation was scanty; she complained of giddiness and aching in her limbs. I ordered her to take fire grains of extract of urtica three times a day.

Nor. 10th. She had taken four drachms, and the eruption was declining. She felt better, and had less pain in her limbs.

Dec. 21st. She was very much better. She had taken one ounce. When giddy, I ordered her to take an aperient.

Jan. 27th, 1853. She was quite well, having taken another ounce. As she had not menstruated, she was ordered to take iron.

Case xir. Mrs. W., a fat florid woman, about 50, had had for six years lichen agrius; chiefly over the extensors of both arms, and of the skin covering the chest, back, and abdomen. She had been under treatment by various practitioners without benefit. At one time, she was ten months continuously under one, and at another period six months under another, until "she was tired of taking medcine". The itching was considerable. In addition to getting the secretions right by alterative mercurials and aperients, she was directed to take a quarter of a pint daily of the decoction of nettle, and subsequently fire grains of the extract twice a day. She began on May 18th, and on the 29th of August, the eruption, which had gradually declinsed, was quite well, and remained so when I saw her five weeks afterwards.

Case xIII. Mrs. A., aged 43, July 9th, 1854, for six months had had lichen agrius of both arms. Both legs were affected with a diffused deep red eruption, with much itching, but without discharge. Sulphur ointment was applied to the legs; five grains of compound rhubarb pill were taken every night; and five grains of the extract of urtica twice a day.

July 31st. She had taken one ounce of the extract, and was much better.

Aug. 7th. The legs were nearly well, but there was rather more eruption of lichen. The extract was omitted.

Aug. 21st. The lichen was in the same state. She was ordered to resume the urtica.

Aug. 28th. The lichen was well, and the legs also.

In this case, as not unfrequently happens, the urtica seems occasionally to aggravate the eruption; and, in the following, it seemed to bring it out, tending to show its real efficacy on the system.

CASE XIV. A. T., aged 44 , a tallor, had inveterate psoriasis palmaria, of four months' standing; both palms were covered with dry hard epidermis, and tender from numerous chaps. He was directed to apply glycerine, and to take a quarter of a pint of the decoction of urtica daily. After taking the decoction for a week, he became almost covered with a papular eruption of lichen, which itched considerably. His hands felt better. On omitting the nettle, the papular eruption declined and desquamated. He resumed it, and, with the constant use of glycerine, his hands, when he last called on me, were almost well, and quite comfortable.

These are a few out of a much larger number of cases in which I have tried the urtica during the last two or three years, as extract and decoction. From this experience, it seems to be particularly indicated in inveterate chronic papular eruptions (lichen), and in various forms of resicular 


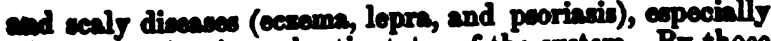
when coourring in cachectic states of the syatem. BJ those when in the country as parochial surgeons, who have mmerous caces of chronic skin diseases in unhealthy children, and who have not already employed this remedy, it is wecth a trial, from the facility with which it can be procorred by the poor.

It is hardly necessary to add that, if the tongue is loaded, it is advisable to commence with mild mercurials and aperients, before the urtica is used; and that, in all cases, a plain wholesome diet, and frequent washing of the whole akin, are to be recommended. Indeed, to prevent the return of akin disenses which have been of long standing, it is of primary importance that the whole surface of the body chould be washed daily with soap and water; for, as cruptions are often the means which nature sets up for relieving a faulty state of the system through the skin, it is rational to suppose that a free and perspirable condition of that extensive surface will assist nature in removing her maste matter, and thus will prevent the necessity of this scaly, or papular, or vesicular action. What the older practitioners attempted by means of issues may be more naturally effected by the daily use of soap and water to the rhole cutaneous surface. In one case, this practice alone, steadily persevered in for several months, and continued as asit, permanently cured psoriasis palmaria of more than trenty years' duration.

Washing the whole surface daily with soap and water will be found to be a very servicesble recommendation, not as a mere matter of cleanliness, but as one of the directions for the general treatment of many chronic diseases, and for the preservation of health in advancing life. Its effect is very different to that of merely washing the body with cold water, or using shower-baths, or bathing followed by dry friction. It does not give the same shock as cold water alone; and it is thus much more easily borne by the delicate, who find that the reaction after cold sponging is exhnusting. It more effectually removes the waste epidermis than flesh-brushes or hair-gloves; and suits those whose delicate skins are often irritated into eruptions by these rough appliances. For those who are very subject to colds, and are yet tco delicate to bear cold sponging, the addition of soap, by its stimulating property, acts as a tonic to the skin, and thus guards it against the effects of sudden changes of temperature, besides aiding in getting rid of the waste and superfluous matters, which often require the actions which constitute a cold for their discharge from the overloaded system. The yellow soap, from the resin it contains, is an excellent stimulant as well as detergent; and a better still, in many cases, is a soap containing a small quantity of Barbadoes tar, called Hendrie's petroline soap, the daily use of which is peculiarly serviceable in keeping up a smooth and perspirable state of the skin when it is naturally dry, and especially in declining life, when the loss of muscular power prevents exercise carried to perspiration; for, as man is organised to earn his bread by the sweat of his brow, if he cannot do this, he must use some artificial means to produce the same state of his perspiring organ, or he will suffer. A physician, distinguished in his day in a neighbouring county, who nuw, though verging on 90 , retains a freshness and vigour of intellect, as well as a sound condition of health, which enable him to enjoy his existence physically and socially, and to devote a portion of each day to the cultivation of science, informed me that he attributed much of his health and activity to this daily soaping of his skin, which he had persevered in since he was a very joung man. And the elderly, who usually have much opare time at their disposal, will find that the employment of a portion of it daily in this way will repay them for the pains. In the management of the disorders of the general health which 80 often attend the cessation of menstruation, this practice is, for obvious reasons, to be recommended.

Sonthampton, Norember 1854
ON THE COMMUNICATIONS BETWEEN THE LYMPHATIC SYSTEM AND THE VENNS:

PBOVISIONAL REPORT FROX THE LONDON COMMTYTES OT ERO

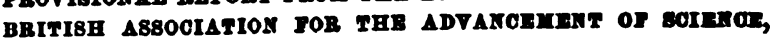
APPOMTED TO YAKE AI EXPERIMENTAS IXQUIRT IAYO THIS SUBJECT.

By THOMAS HODGKIN, M.D.

[Read to the Medical Section of the British Association, at its Heeting at Bristol, 1836.1

[In physiology, as in medicine, some subjects may be said for a time to be fashionable, or at least to excite a temporary interest, and then to be lost sight of or become obsolete. This is somewhat the case with the function of absorption; nevertheless, I have thought that the following unpublished paper, which was written for the Medical Section of the British Association for the Adrancement of Scienco-a section which the formation of the Provircial Medical Association has superseded-might not be unworthy of a place in the Jod BNAL, in order that some of the facts which it records may be preserved. T. H.]

Tho Medical Section of the British Association for the Promotion of Science was induced at its meeting in Edinburgh to name a commission to make an experimental inquiry into the mutual relation existing between the venous, lymphatic, and lacteal systems; but the principal object of inquiry was stated to be to settle the question as to the existence or absence of the numerous communications between the two systems, occasioned by the lacteals and lymphatics in different parts of the body emptying themselves into the veins by a shorter course than those of the thoracic duct and right trunk; the affirmative of this having been stated by Fohmann and Louth, and more strongly insisted upon by Lippi; and the negatire being affirmed with equal confidence by Panizza and other able anatomists. To facilitate the operations of the commission, it was composed of two sections; the one meeting in Edinburgh, the other in Loudon. Amongst the Edinburgh Section were two gentlemen justly esteemed as able practical anatomists and physiologists, Drs. Sharpey and Allen Thomson, who had already been engaged in this inquiry, and have not failed to continue the research, in compliance with the wishes of the Association. I am uncertain whether any report was made by them to the meeting in Dublin; but their views at least have been given to the public in an excellent paper from the pen of one of these gentlemen, Allen Thomson, which may be found in No. cxxv of the Edinburgh and Medical and Surgical Journal.

With respect to the London Section, which consisted of Dr. Roget, Dr. Clark of Cambridge, W. Clift, Bracy Clark, Richard Owen, and myself, I regret to say that, though troo years have nearly passed, we have done very little towards the completion of tho task assigned to us. This must be in part ascribed to the difficulty which we have found in combining for the purpose of making researches requiring 80 much continued and undivided attention, and so much practical skill in manipulation, in conjunction with favourable opportunities neither to be commanded nor anticipated.

As we have not been altogether inactive, we have thought it right to make a provisional report of progress, and at the same time to request permission to act for another year. I have therefore druwn up the following communication.

It soon appeared to us that the Anatomical School at Guy's Hospital was likely to furnish the greatest facilities for the practical part of this inquiry; and, as a further assistance, we have associated with us Francis Bibson, jun. (now Dr. Bibson) and (the late) Thomas King, both justly esteemed as able practical anstomists and zealous physiological inquirars. It is to their assistance that I am indebted for the examination by means of mercurial injection of cereral subjects, in whom the sice and viaibility of the Ijmphatic astem promined facilitios for the inguing. Ip 